\title{
A randomized, crossover study of the acute effects of acarbose and gastric distension, alone and combined, on postprandial blood pressure in healthy older adults
}

Hung Pham ${ }^{1}$, Laurence Trahair ${ }^{1}$, Liza Phillips ${ }^{1,2}$, Christopher Rayner ${ }^{1,3}$, Michael Horowitz ${ }^{1,2}$ and Karen Jones ${ }^{1,2^{*}}$ (D)

\begin{abstract}
Background: Postprandial hypotension (PPH) occurs frequently in the elderly and patients with type 2 diabetes, and lacks a satisfactory treatment. Gastric distension and the a-glucosidase inhibitor, acarbose, may attenuate the postprandial fall in blood pressure (BP) by complementary mechanisms. We aimed to determine whether gastric distension and acarbose have additive effects to attenuate the fall in BP induced by oral sucrose.

Methods: Ten healthy older adults (74.0 $\pm 1.4 \mathrm{yr}$ ) had measurements of BP and superior mesenteric artery (SMA) blood flow for $120 \mathrm{~min}$ after receiving either (i) the 'study drink' of $100 \mathrm{~g}$ sucrose in $300 \mathrm{~mL}$ of water (control treatment), (ii) a $300 \mathrm{~mL}$ water 'preload' $15 \mathrm{~min}$ before the 'study drink' (distension treatment), (iii) $100 \mathrm{mg}$ acarbose dissolved in the 'study drink' (acarbose treatment) or (iv) a $300 \mathrm{ml}$ water 'preload' 15 min before $100 \mathrm{mg}$ acarbose dissolved in the 'study drink' (acarbose and distension treatment).

Results: The area under the curve (AUC) $)_{0-120 \mathrm{~min}}$ for mean arterial pressure (MAP) was greater $(P=0.005)$ and the maximum fall in MAP was less $(P=0.006)$ during treatments with acarbose. Gastric distension did not affect the MAP-AUC $C_{0-120 m i n}$ response to acarbose $(P=0.44)$ and there was no effect of gastric distension alone $(P=0.68)$. Both acarbose treatments attenuated the rise in SMA blood flow $(P=0.003)$, whereas gastric distension had no effect.

Conclusions: In healthy older adults, acarbose $(100 \mathrm{mg})$, but not gastric distension, attenuates the fall in BP and rise in SMA blood flow after oral sucrose. The observations support the use of acarbose, but not gastric distension, to attenuate a postprandial fall in BP.
\end{abstract}

Trial registration: The study was retrospectively registered at (ACTRN12618000152224) on February 02nd 2018.

Keywords: Postprandial hypotension, Acarbose, Gastric distension

\section{Background}

Postprandial hypotension ( $\mathrm{PPH})$, usually defined as a fall in systolic blood pressure (BP) of $\geq 20 \mathrm{mmHg}$, within $2 \mathrm{~h}$ of a meal $[1,2]$, occurs frequently, e.g. in $24-38 \%$ of 'healthy' older adults [3] and $25-40 \%$ of patients with type 2 diabetes (T2DM) [2, 4], and is associated with major adverse sequelae, including syncope and falls $[1,2]$, as well

\footnotetext{
* Correspondence: karen.jones@adelaide.edu.au

${ }^{1} \mathrm{NHMRC}$ Centre of Research Excellence in Translating Nutritional Science to Good Health, Adelaide Medical School, The University of Adelaide, Level 5 Adelaide Health and Medical Sciences Building, Cnr North Tce and George St, Adelaide, SA 5005, Australia

2Endocrine and Metabolic Unit, Royal Adelaide Hospital, Adelaide, Australia Full list of author information is available at the end of the article
}

as increased mortality [3]. Current management is suboptimal [4].

The pathophysiology of PPH is heterogeneous, which may account for the lack of effective management. Multiple factors appear to be involved, including autonomic dysfunction, the release of gastrointestinal hormones, meal composition, gastric distension, and small intestinal nutrient delivery. After a meal, there is substantial splanchnic blood pooling [2], and in healthy young individuals, baroreflex mechanisms protect against a postmeal decrease in BP through compensatory increases in heart rate (HR), stroke volume and cardiac output [5]. In 'healthy' older adults and in patients with $\mathrm{PPH}$, these

(c) The Author(s). 2019 Open Access This article is distributed under the terms of the Creative Commons Attribution 4.0 International License (http://creativecommons.org/licenses/by/4.0/), which permits unrestricted use, distribution, and reproduction in any medium, provided you give appropriate credit to the original author(s) and the source, provide a link to the Creative Commons license, and indicate if changes were made. The Creative Commons Public Domain Dedication waiver (http://creativecommons.org/publicdomain/zero/1.0/) applies to the data made available in this article, unless otherwise stated. 
compensatory responses are inadequate to maintain BP [2]. We have shown in healthy older adults and people with T2DM that the magnitude of the postprandial fall in $\mathrm{BP}$ is greater when the rate of gastric emptying [6], or direct small intestinal nutrient delivery $[7,8]$, is relatively more rapid. For example, when glucose is infused into the duodenum at rates spanning the normal physiological range, a $3 \mathrm{kcal} / \mathrm{min}$ load induces a much greater decrease in $\mathrm{BP}$ and rises in $\mathrm{HR}$ and superior mesenteric artery (SMA) blood flow than $1 \mathrm{kcal} / \mathrm{min}$ [8]. Moreover, $\mathrm{PPH}$ is associated with more rapid gastric emptying [9]. In contrast to the effect of small intestinal nutrient delivery, gastric distension appears to be protective in $\mathrm{PPH}$. Drinking water with a meal has been reported to attenuate the postprandial fall in BP in healthy older adults $[10,11]$, as well as in patients with autonomic failure [10-12], probably primarily by inducing gastric distension. For example, Gentilcore et at (2008) reported that gastric distension with water at a volume as low as 300 $\mathrm{mL}$ diminished the fall in $\mathrm{BP}$ in response to intraduodenal glucose in the healthy elderly [13]. The pressor response to water may also be greater in patients with autonomic failure [11].

The alpha-glucosidase inhibitor, acarbose, is used widely in the management of T2DM. By delaying intestinal disaccharide absorption, it reduces postprandial glycemia [14]. Acarbose also stimulates the release of the incretin hormone, glucagon-like peptide-1 (GLP-1) [15], and slows gastric emptying [16], which may contribute to glucose lowering in T2DM. We reported previously that acarbose $(100 \mathrm{mg})$ attenuated the fall in systolic BP induced by oral sucrose in healthy older adults, an effect associated temporally with slowing of gastric emptying and stimulation of GLP-1 [17]. However, when administered intraduodenally i.e. bypassing any effect of slowing gastric emptying, acarbose also attenuated the fall in BP induced by sucrose [18], which may reflect an effect of acarbose to reduce splanchnic blood flow [18]. Subsequent studies support the efficacy of acarbose in the management of PPH to attenuate $[19,20]$, but not abolish, the fall in BP, although these have, for the main part, employed small cohorts and associated with substantial methodological limitations. Somewhat surprisingly, only one study has hitherto evaluated the effect of acarbose $(50 \mathrm{mg})$ on the splanchnic blood flow response to a meal [21], which appears central to the hypotensive response. Furthermore, this study was in a heterogeneous group of individuals with $\mathrm{PPH}$ and was neither randomised nor blinded in design, compromising meaningful interpretation [21].

While it is apparent that gastric distension (induced by water drinking) and acarbose theoretically have complementary effects to attenuate the postprandial fall in BP, this has hitherto not been evaluated, which is surprising given the simplicity and safety of both approaches. The aim of this study was to determine the acute effects of water drinking and acarbose, alone and combined, on the BP and SMA blood flow responses to oral sucrose. To establish 'proof-of-principle', we studied a cohort of healthy older adults, rather than patients with PPH.

\section{Methods \\ Subjects}

Ten healthy older adults living in the community (2 male, and 8 female, mean age $74.0 \pm 1.4$ years, BMI $26.2 \pm 1.1 \mathrm{~kg} /$ $\mathrm{m}^{2}$ ) were recruited by advertisements placed around the hospital, in newspapers and via social media, and from a database of subjects who had participated in research studies and consented to be contacted. All healthy subjects were non-smokers and none had a history of gastrointestinal disease or surgery, diabetes, significant respiratory, renal or cardiac disease, chronic alcohol abuse, epilepsy, or was taking medication known to influence BP or gastrointestinal function. The study was conducted in accordance with the Declaration of Helsinki following the provision of written informed consent by each of the participants. The study was registered at http://www.ANZCTR.org.au (ACTR N12618000152224) and approved by the Human Research Ethics Committee of the Royal Adelaide Hospital. The study adheres to CONSORT guidelines.

\section{Protocol}

Each subject was studied on 4 occasions, separated by at least 1 week, in a randomized, crossover design. On each study day, the subject attended the University of Adelaide, Discipline of Medicine at the Royal Adelaide Hospital at $\sim 09.00 \mathrm{~h}$ after an overnight fast (14 $\mathrm{h}$ for solids; $12 \mathrm{~h}$ for liquids) [22]. Subjects were seated in a chair, an intravenous cannula was inserted into an antecubital vein for blood sampling and an automated BP cuff placed around the opposite arm. Following a period of 'rest' of 15-30 min to allow baseline BP to stabilise [7], subjects were given, in random order, either the (i) control treatment $(\mathrm{C})$ : a test drink comprising $100 \mathrm{~g}$ sucrose dissolved in $300 \mathrm{~mL}$ of water $(\sim 407 \mathrm{kcal})$, (ii) distension treatment (D): a 'preload' of $300 \mathrm{~mL}$ water $15 \mathrm{~min}$ before the ingestion of the test drink, (iii) acarbose treatment (A): $100 \mathrm{mg}$ acarbose (Glucobay ${ }^{\mathrm{Tm}}$, Bayer Schering Pharma AG, Berlin, Germany) dissolved in the test drink or (iv) combined treatment (AD): the water preload was given 15 min before the ingestion of acarbose which was dissolved in the test drink. Both the 'preload' and test drink were consumed within 2 min with time zero $(t=0$ min) defined as the end of test drink ingestion (Fig. 1).

Measurements of BP, HR and SMA blood flow were performed at regular intervals until $t=120 \mathrm{~min}$, as the greatest fall in postprandial BP is known to occur within that time [3]. At the end of each study day, each subject 


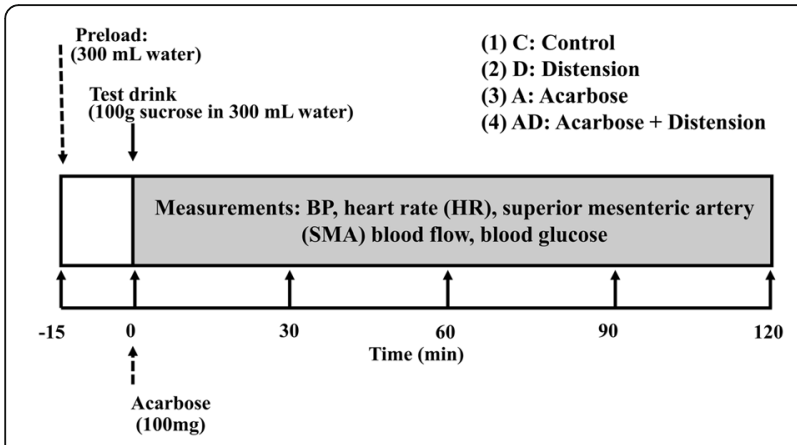

Fig. 1 Schema of the study protocol

was provided with lunch and a final BP measurement was taken prior to them leaving the laboratory.

\section{Measurements}

\section{Blood pressure and heart rate}

Systolic and diastolic BP (SBP and DBP) and HR were measured with an automated oscillometric BP monitor (DINAMAP ProCare 100, GE Medical Systems, Milwaukee, WI, USA) at 3-min intervals prior to ingesting the test drink, and, subsequently, every 3 min between $t=0-120$ min $[6,8,13,17,23-29]$. An average of BP and HR measurements obtained at $\mathrm{t}=-24,-21,-18 \mathrm{~min}$ prior to the ingestion of the preload ( $t=-15 \mathrm{~min})$, or, on the study day without a preload, at $\mathrm{t}=-9,-6,-3 \mathrm{~min}$ prior to ingestion of the test drink, were calculated to represent baseline BP and HR. The mean arterial pressure (MAP) was calculated using the formula $\mathrm{MAP}=\mathrm{DBP}+[(\mathrm{SBP}-$ $\mathrm{DBP} / 3$ ]. PPH was defined as a fall in systolic BP of at least $20 \mathrm{mmHg}$ that was sustained for $30 \mathrm{~min}$ or more [6].

\section{Superior mesenteric artery blood flow}

SMA blood flow $(\mathrm{mL} / \mathrm{min})$ was measured prior to the ingestion of the preload $(\mathrm{t}=-17 \mathrm{~min})$ and/or test drink $(t=-2 \mathrm{~min})$, and then every $15 \mathrm{~min}$ between $\mathrm{t}=0-120$ min using a Logiq $\mathrm{e}^{\mathrm{mm}}$ ultrasound system (GE Healthcare Technologies, Sydney, NSW, Australia) incorporating a $3.5 \mathrm{C}$ broad spectrum $2.5-4 \mathrm{MHz}$ convex linear array transducer [30].

\section{Blood glucose concentrations}

Venous blood samples $(\sim 15 \mathrm{~mL})$ were drawn immediately before ingestion of the preload $(t=-17 \mathrm{~min})$ and /or test drink $(t=-2 \mathrm{~min})$ and then at $\mathrm{t}=30,60,90$ and $120 \mathrm{~min}$. Blood glucose concentrations were determined during the study using a portable glucometer (Medisense Companion 2 Meter, Medisense Inc., Waltham, MA, USA) [31].

\section{Autonomic nerve function}

Autonomic nerve function was assessed on one of the 4 days using standardized cardiovascular reflex tests with an appropriately sized BP cuff in a temperature-controlled, quiet, clinical study room (ANX-3.0 autonomic monitoring system (ANSAR Medical Technologies, Inc., Philadelphia, PA)) [32-34]. Testing was performed in the fasting state, preceded by $10-15$ min of rest in the recumbent position. Parasympathetic function was evaluated by: i) the variation ( $R-R$ interval) of the HR during deep breathing whereby 6 respiratory cycles were performed and E/I ratio calculated from the peak expiratory and peak inspiratory heart beat intervals and ii) the response to standing (30:15 ratio), with the relevant ECG parameters captured and analyzed electronically [32]. Sympathetic function was assessed by the fall in systolic BP in response to standing whereby baseline BP was taken following $10-15 \mathrm{~min}$ in a semi-recumbent position immediately and $3 \mathrm{~min}$ after standing. An abnormal BP response to standing was defined as a decrease in BP of 20/10 $\mathrm{mmHg}$ or more upon standing over resting. Each of the test results was scored according to predefined criteria that were adjusted for age where 0 was considered normal, 1 as borderline, and 2 as abnormal providing a total maximum score of 6 [34]. A score of at least 3 was considered to suggest autonomic dysfunction.

\section{Statistical analysis}

The maximum fall in MAP and rise in HR were defined as the greatest change from baseline in each subject at any given time point for each treatment. Areas under the curve (AUCs) were calculated using the trapezoidal rule from $t=0-120$ min for MAP and HR, and from $t=-2$ $120 \mathrm{~min}$ for SMA blood flow and blood glucose. Repeated measures two-factor ANOVA was used to evaluate the effects of acarbose, gastric distension and their interaction for the AUCs for MAP, HR, SMA blood flow and blood glucose. All analyses were performed using SPSS version 23 (SPSS, Chicago, IL, USA). MAP and HR are presented as change from baseline values and SMA blood flow and blood glucose concentrations as absolute values. Data are presented as mean values \pm SEM, unless stated otherwise. A $P$ value $<0.05$ was considered significant in all analyses.

\section{Results}

The studies were reasonably well tolerated. Flatulence and/or diarrhea were reported by 3 of the 10 subjects on acarbose days; in each case the onset of symptoms was about 3-4h after ingestion. Three subjects fainted during the study ( 2 subjects on the distension day and 1 on the acarbose day between $t=60-75 \mathrm{~min}$ ), which, in each case, resolved promptly after lying supine for $15-30 \mathrm{~min}$. In 1 of the 3 subjects, fainting was concordant with PPH on the distension day. No subject had autonomic neuropathy (mean score: $1.4 \pm 0.2$ ). In 1 subject, the ultrasound images of SMA blood flow were suboptimal on all study days due to the presence of bowel gas, precluding 
their use. In another subject, insertion of the intravenous cannula for blood sampling was unsuccessful on all 4 study days due to poor venous access. Accordingly, BP and HR data are available in 10, while SMA blood flow and blood glucose data are available in 9, subjects.

\section{Blood pressure and heart rate}

There were no differences in baseline BP or HR among the 4 treatments (control vs. distension vs. acarbose vs. combined treatment, respectively): SBP $(133 \pm 3.7 \mathrm{mmHg}$ vs. $128 \pm 2.8 \mathrm{mmHg}$ vs. $125 \pm 3.6$ $\mathrm{mmHg}$ vs. $129 \pm 3.7 \mathrm{mmHg} ; P=0.19) ; \mathrm{DBP}(72 \pm 2.6$ $\mathrm{mmHg}$ vs. $73 \pm 2.8 \mathrm{mmHg}$ vs. $70 \pm 1.9 \mathrm{mmHg}$ vs. $73 \pm$ $1.7 \mathrm{mmHg} ; \quad P=0.23) ; \quad$ MAP $(92 \pm 2.2 \mathrm{mmHg}$ vs. $91 \pm$ $2.4 \mathrm{mmHg}$ vs. $88 \pm 2.1 \mathrm{mmHg}$ vs. $92 \pm 1.9 \mathrm{mmHg} ; P=$ $0.18)$ and HR $(67 \pm 2.1$ beats/min vs. $68 \pm 2.5$ beats/ min vs. $66 \pm 2.8$ beats $/ \mathrm{min}$ vs. $67 \pm 2.6$ beats $/ \mathrm{min} ; P=$ $0.76)$. One subject on the control day and another on the distension day had $\mathrm{PPH}$. No subject experienced $\mathrm{PPH}$ on either of the acarbose study days.

\section{Mean arterial pressure}

Between $\mathrm{t}=0-120 \mathrm{~min}$, there was a fall in MAP during control and distension treatments $(P<0.001$ for both), but no overall change during either acarbose $(P=0.44)$, albeit a non-significant trend for combined $(P=0.06)$, treatments. There was a treatment effect for acarbose, so that the $\mathrm{AUC}_{0-120 \mathrm{~min}}$ for MAP was greater during treatments with acarbose (A: 10,625 $\pm 237 \mathrm{mmHg}$.min and AD: $10,721 \pm 232 \mathrm{mmHg} \cdot \mathrm{min} ; \quad P=0.005)$ compared to control (C: $10,366 \pm 281 \mathrm{mmHg} \cdot \mathrm{min})$, but not for distension (D: $10,106 \pm 252 \mathrm{mmHg} \cdot \mathrm{min} ; P=0.68$ ). There was also no interactive effect between acarbose and distension on the $\mathrm{AUC}_{0-120 \mathrm{~min}}$ for MAP $(P=0.44)$ (Fig. 2a).

The maximum fall in MAP from baseline was less during treatments with acarbose $(P=0.006)$ (acarbose: $6.9 \pm 1.8 \mathrm{mmHg}$ and combined treatment: $-8.2 \pm 1.5$ $\mathrm{mmHg})$ compared with control $(-12.2 \pm 1.4 \mathrm{mmHg})$. There was no effect of gastric distension alone $(-15.3 \pm$ $1.8 \mathrm{mmHg}, P=0.21)$ and no difference between the acarbose treatments with or without gastric distension $(P=$ 0.58 ).
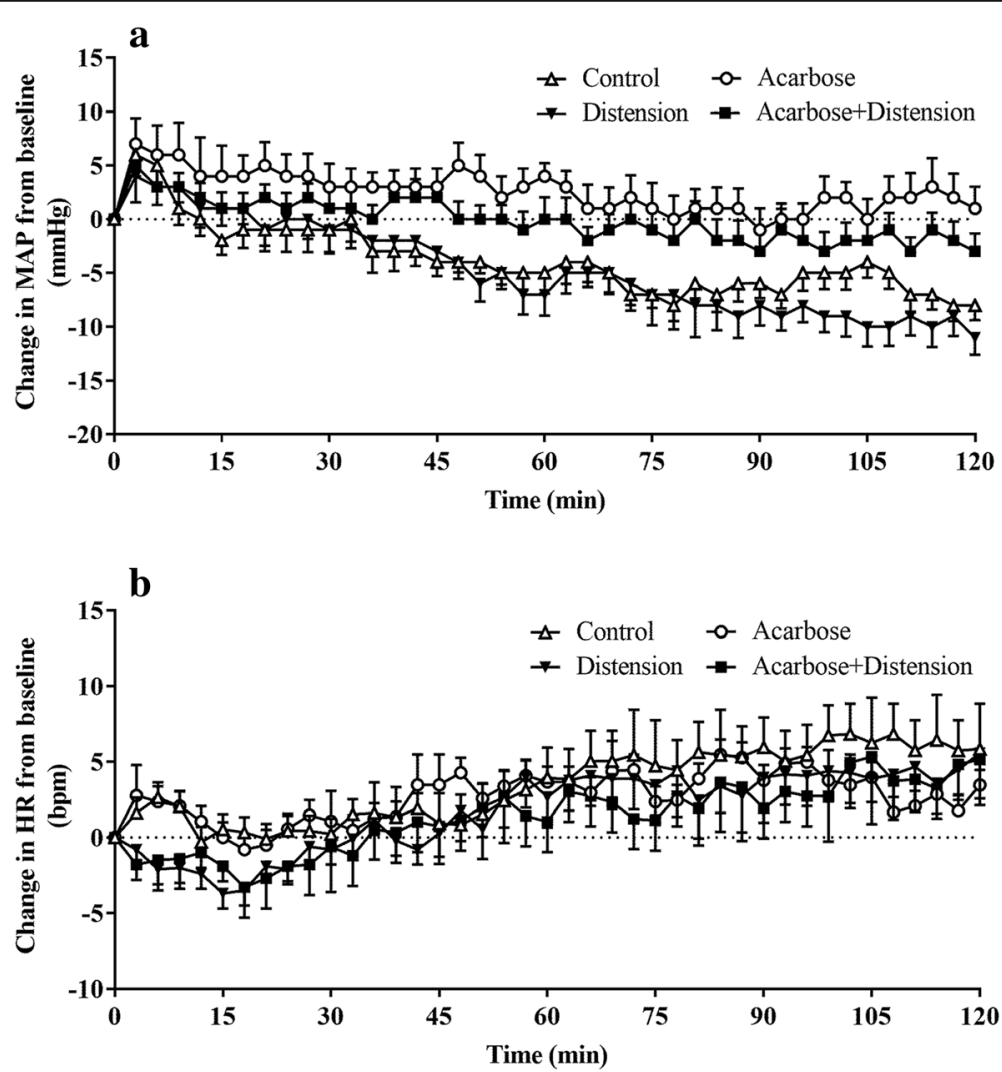

Fig. 2 Changes in mean arterial pressure (MAP) (a), and heart rate (HR) (b) from baseline in response to control (C), distension (D), acarbose (A) and combined (AD) treatments. Data are mean values $\pm \operatorname{SEM}(n=10)$. The $A \cup C_{0-120}$ for MAP was greater $\left(A\right.$ and $A D$ compared to $\left.C_{;} P=0.005\right)$ with both acarbose treatments with no difference between $C$ and $D$. The $A \cup C_{0-120}$ for HR was less ( $A$ and $A D$ compared to $C ; P=0.04$ ) with both acarbose treatments with no difference between $C$ and $D$ 


\section{Heart rate}

Between $\mathrm{t}=0-120 \mathrm{~min}$, there was a rise in HR among 4 treatments $(P<0.005$ for all) (Fig. 2b). There was a treatment effect for acarbose, so that the $\mathrm{AUC}_{0-120 \mathrm{~min}}$ for $\mathrm{HR}$ was lower during treatments with acarbose (A: $8057 \pm$ $356 \mathrm{bpm} . \mathrm{min}$ and AD: $7985 \pm 315 \mathrm{bpm} . \mathrm{min} ; \quad P=0.04$ ) compared to control (C: $8252 \pm 357$ bpm.min), but not for distension (D: $8165 \pm 312$ bpm.min; $P=0.55$ ). There was also no interaction between acarbose and distension on the $\mathrm{AUC}_{0-120 \mathrm{~min}}$ for $\mathrm{HR}(P=0.92)$ (Fig. 2b).

There was no treatment effect for the maximum rise in HR from baseline among the 4 treatments, so that there was no significant difference in the maximum rise in HR during acarbose $(10.4 \pm 1.4 \mathrm{bpm}, P=0.93)$, distension $(10.5 \pm 1.9 \mathrm{bpm}, P=1.0)$ and combined treatments (10.6 $\pm 2.4 \mathrm{bpm}, P=0.88)$, compared to control $(10.7 \pm$ $2.5 \mathrm{bpm})$.

\section{Superior mesenteric artery blood flow}

There was no difference $(P=0.83)$ in baseline $(\mathrm{t}=-2$ min) SMA blood flow among the 4 treatments (control vs. distension vs. acarbose vs. combined treatment: $543 \pm 55 \mathrm{~mL} / \mathrm{min}$ vs. $583 \pm 91 \mathrm{~mL} / \mathrm{min}$ vs. $538 \pm 75 \mathrm{~mL} /$ min vs. $579 \pm 50 \mathrm{~mL} / \mathrm{min}$, respectively) (Fig. 3).

Between $\mathrm{t}=-2-120 \mathrm{~min}$, there was a rise in SMA blood flow with the control $(P<0.001)$ and distension $(P=0.02)$, and a trend for an increase after acarbose alone $(P=0.08)$ and combined $(P=0.07)$, treatments (Fig. 3). There was a treatment effect for the $\mathrm{AUC}_{0-}$ $120 \mathrm{~min}$ of SMA blood flow for acarbose, so that SMA blood flow was less during acarbose treatments, with or without distension (A: 86,689 $\pm 10,725 \mathrm{~mL} / \mathrm{min}$.min and AD: $87,720 \pm 6750 \mathrm{~mL} / \mathrm{min} . \mathrm{min} ; \quad P=0.003)$, compared with control (C: $111,738 \pm 12,631 \mathrm{~mL} / \mathrm{min} . \mathrm{min})$. There was no difference between distension (D: 95,846 \pm 11 ,

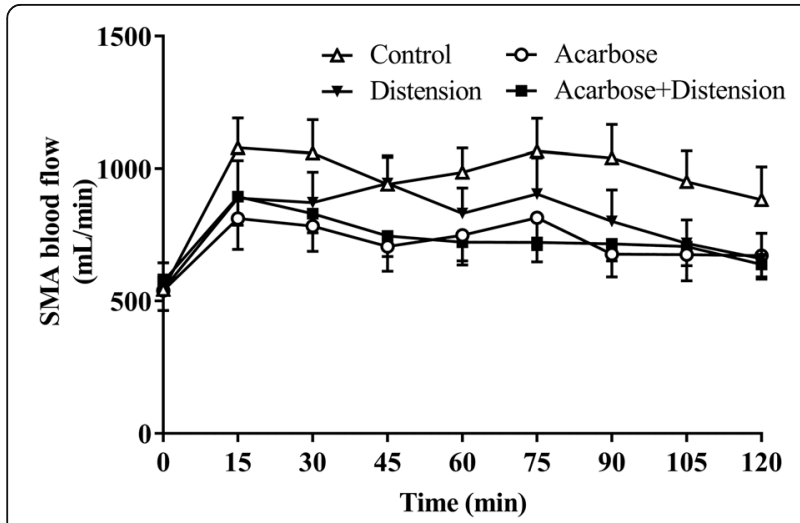

Fig. 3 Superior mesenteric artery blood flow in response to control $(C)$, distension (D), acarbose (A) and combined (AD) treatments. Data are mean values \pm SEM $(n=9)$. The $\mathrm{AUC}_{0-120}$ for SMA flow was less ( $A$ and $A D$ compared to $C_{;} P=0.003$ ) with both acarbose treatments with no difference between $C$ and $D$
$418 \mathrm{~mL} / \mathrm{min} . \mathrm{min})$ and control $(P=0.41)$, and no additive effect between acarbose and distension in the combined treatment $(P=0.15)$ (Fig. 3).

The maximum rise in SMA blood flow during acarbose treatments (acarbose: $963 \pm 123 \mathrm{~mL} / \mathrm{min}$ and combined treatment: $983 \pm 102 \mathrm{~mL} / \mathrm{min})$ was less $(P=0.03)$, compared to control $(1173 \pm 111 \mathrm{~mL} / \mathrm{min})$. There was no difference between distension $(1073 \pm 140 \mathrm{~mL} / \mathrm{min}) \quad(P=0.67)$ and control and no interaction between acarbose and distension $(P=0.42)$ in the maximum rise in SMA blood flow (Fig. 3).

\section{Blood glucose}

There was no difference $(P=0.56)$ in baseline $(t=-2$ min) blood glucose among the 4 treatments (control vs. distension vs. acarbose vs. combined treatment: $5.6 \pm$ $0.16 \mathrm{mmol} / \mathrm{L}$ vs. $5.6 \pm 0.14 \mathrm{mmol} / \mathrm{L}$ vs. $5.6 \pm 0.10 \mathrm{mmol} / \mathrm{L}$ vs. $5.7 \pm 0.20 \mathrm{mmol} / \mathrm{L}$, respectively) (Fig. 4).

Between $\mathrm{t}=-2-120 \mathrm{~min}$, there was a rise in blood glucose with all treatments $(P<0.001$ for all) (Fig. 4). There was a treatment effect for the $\mathrm{AUC}_{0-120 m i n}$ for blood glucose for acarbose, so that blood glucose was less during acarbose treatments with and without distension (A: $827 \pm 28.9 \mathrm{mmol} / \mathrm{L} . \mathrm{min}$ and AD: $863 \pm 30.3 \mathrm{mmol} / \mathrm{L} . \mathrm{min}$; $P=0.03$ ), compared with control (C: $919 \pm 41.9 \mathrm{mmol} /$ L.min). There was no difference between distension (D: $948 \pm 53.9 \mathrm{mmol} / \mathrm{L} \cdot \mathrm{min})$ and control $(P=0.12)$, nor any additive effect between acarbose and distension when combined $(P=0.92)$ (Fig. 4$)$.

\section{Discussion}

Our study evaluated the acute effects of acarbose and water drinking, alone and combined, on the BP and SMA blood flow responses to oral sucrose in healthy older adults. We demonstrated that in this group,

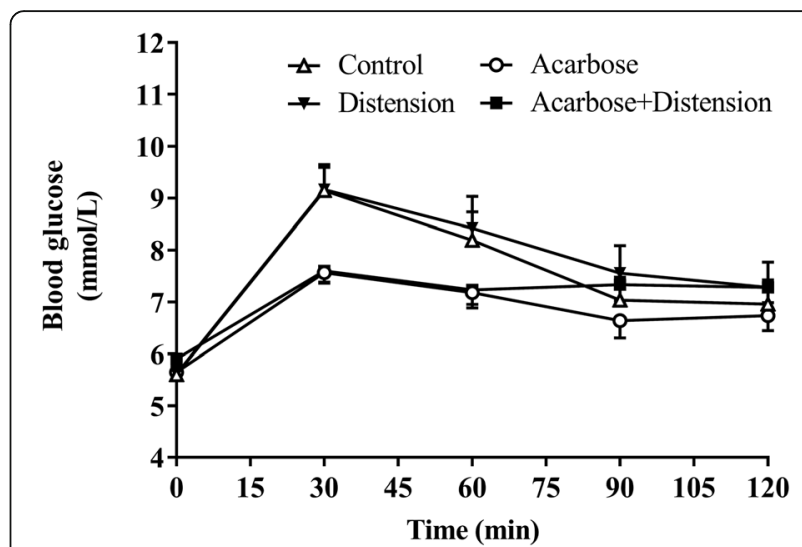

Fig. 4 Blood glucose concentrations in response to control (C), distension (D), acarbose (A) and combined (AD) treatments. Data are mean values $\pm \operatorname{SEM}(n=9)$. The $\mathrm{AUC}_{0-120}$ for blood glucose was reduced ( $A$ and $A D$ compared to $C ; P=0.03$ ) by both acarbose treatments with no difference between $C$ and $D$ 
ingestion of sucrose induced a substantial increase in SMA blood flow and fall in BP, as predicted [17, 18]. These changes were essentially abolished by acute administration of acarbose in a dose of $100 \mathrm{mg}$; which was well tolerated. In contrast, water drinking alone $(300 \mathrm{~mL}$, 15 min before the sucrose load) to induce gastric distension had no significant effect on either BP or splanchnic blood flow and did not modify the response to acarbose.

This is the first study to evaluate the interaction between acarbose and gastric distension on 'postprandial' BP based on their potential for synergetic, or additive, effects. The observed responses to acarbose are consistent with previous reports, including our own $[17,18,21$, 35], and support the concept that acarbose will be useful in the management of $\mathrm{PPH}$. We have further demonstrated that acarbose causes a profound attenuation of the rise in SMA blood flow induced by oral sucrose [18, 21] which is likely to be central to its anti-hypotensive effect. Such an effect was suggested in a previous study that was methodologically flawed [21]. The reduction in the splanchnic blood flow response to oral sucrose induced by acarbose is likely to reflect mechanisms unrelated to slowing of gastric emptying per se [17], given that the increase in SMA blood flow induced by intraduodenal administration of sucrose in healthy older adults is also markedly attenuated by acarbose [18]. The stimulation of GLP-1 as a result of the presence of nutrient in the more distal intestine may be relevant. In particular, we have demonstrated in healthy older adults that intravenous GLP-1 reduces the SMA blood flow response to intraduodenal glucose [36] and that the shortacting' GLP-1 agonist, lixisenatide, prevents the fall in systolic BP and reduces the rise in SMA flow following a $75 \mathrm{~g}$ oral glucose load in healthy older subjects and T2DM patients [37]. However, in relation to a role for endogenous GLP-1, it would be expected that stimulation of GLP-1 would be associated with a concurrent equivalent increase in glucagon-like peptide-2 (GLP-2) [38, 39], which would be expected to stimulate SMA blood flow [40]. The reduction in plasma glucose induced by acarbose is predictably associated with a reduction in plasma insulin, which has vasodilatory properties [1].

We were surprised that water drinking had no significant effect on either BP or SMA blood flow. There are a number of potential explanations. We selected a relatively low volume $(300 \mathrm{~mL})$ drink to optimise tolerability, influenced by the outcome of our previous study demonstrating that this intragastric volume of water markedly attenuated the hypotensive response to intraduodenal glucose in healthy older adults [13]. With our study design, it would be anticipated that the majority of water would have been emptied from the stomach in the 15 min before the ingestion of the sucrose. Furthermore, the effects of gastric distension are known to be volumedependent [41]. Hence, we cannot discount the possibility that a larger volume of water, given immediately before the sucrose may have been more effective. Moreover, the pressor effect of water drinking may also reflect changes in plasma osmolality $[10,11]$. While there was a substantial fall in BP in response to sucrose, we studied healthy older adults, rather than patients with $\mathrm{PPH}$, and none had evidence of autonomic neuropathy, although assessment of autonomic nerve function was indirect. The latter may also be of relevance to the negative outcome given that the pressor response to water appears to be exaggerated in patients with autonomic impairment [11]. It should also be appreciated that the number of subjects we studied was relatively small and there were non-significant trends for minor effects of water drinking soon after the sucrose drink. Accordingly, a type 2 error cannot be excluded. In addition, GLP-1 was not measured, which may have provided mechanistic insights into the role of acarbose in modulating postprandial BP. A strength of our study was the inclusion of splanchnic blood flow measurement.

\section{Conclusion}

Previous studies have suggested that both acarbose and gastric distension may be potential approaches to reduce the postprandial fall in BP and our study aimed to evaluate the interaction between these interventions. The outcomes provide additional evidence to support the use of acarbose to attenuate the magnitude of the postprandial fall in BP, but not in combination with water drinking. The latter concept should, however, not be dismissed pending the outcome of further studies with greater subject numbers and particularly in patients with $\mathrm{PPH}$ and where water is consumed immediately prior to a meal.

\section{Abbreviations \\ AUC: Area under the curve; BP: Blood pressure; DBP: Diastolic blood pressure; GLP-1: Glucagon-like peptide-1; GLP-2: Glucagon-like peptide-2; HR: Heart rate; MAP: Mean arterial pressure; PPH: Postprandial hypotension; SBP: Systolic blood pressure; SMA: Superior mesenteric artery; T2DM: Type 2 diabetes}

\section{Acknowledgments}

The authors thank Kylie Lange (Centre of Research Excellence in Translating Nutritional Science to Good Health, University of Adelaide) for her assistance with the statistical analyses.

\section{Authors' contributions}

HP: conducted research, analysed data, interpreted data, wrote and revised manuscript; LT: conducted research, analysed data and reviewed manuscript; LP: interpreted data and reviewed manuscript; CR: conceived and designed research, reviewed manuscript; $\mathrm{MH}$ : conceived and designed research, interpreted data and reviewed manuscript; $\mathrm{KJ}$ : conceived and designed research, interpreted data, reviewed manuscript, approved final version of manuscript. All authors have read and approved the manuscript. 


\section{Funding}

This work was supported by a grant from the Royal Adelaide Hospital [grant number: 2027]. The funding body had no influence on the design of the study or the collection, analysis, or interpretation of the data.

\section{Availability of data and materials}

The datasets used and/or analysed during the current study are available from the corresponding author on reasonable request.

\section{Ethics approval and consent to participate}

The study was retrospectively registered at http://www.ANZCTR.org.au (ACTR N12618000152224), conducted in accordance with the Declaration of Helsinki, and approved by the Human Research Ethics Committee of the Royal Adelaide Hospital (091228). Written informed consent was obtained from all subjects.

\section{Consent for publication}

Not applicable.

\section{Competing interests}

The authors declare that they have no competing interests.

\section{Author details}

${ }^{1} \mathrm{NHMRC}$ Centre of Research Excellence in Translating Nutritional Science to Good Health, Adelaide Medical School, The University of Adelaide, Level 5 Adelaide Health and Medical Sciences Building, Cnr North Tce and George St, Adelaide, SA 5005, Australia. ${ }^{2}$ Endocrine and Metabolic Unit, Royal Adelaide Hospital, Adelaide, Australia. ${ }^{3}$ Gastroenterology and Hepatology Unit, Royal Adelaide Hospital, Adelaide, Australia.

Received: 20 February 2019 Accepted: 18 August 2019

Published online: 30 August 2019

\section{References}

1. Mathias CJ. Postprandial hypotension. Pathophysiological mechanisms and clinical implications in different disorders. Hypertension. 1991;18(5):694-704.

2. Jansen RWMM, Lipsitz LA. Postprandial hypotension: epidemiology, pathophysiology, and clinical management. Ann Intern Med. 1995;122(4): 286-95.

3. Fisher AA, Davis MW, Srikusalanukul W, Budge MM. Postprandial hypotension predicts all-cause mortality in older, low-level care residents. Am Geriatr Soc. 2005:53(8):1313-20.

4. Trahair LG, Horowitz M, Jones KL. Postprandial hypotension: a systematic review. J Am Med Dir Assoc. 2014;15:394-409.

5. Jansen RW, Peeters TL, Van Lier HJ, Hoefnagels WH. The effect of oral glucose, protein, fat and water loading on blood pressure and the gastrointestinal peptides VIP and somatostatin in hypertensive elderly subjects. Eur J Clin Investig. 1990;20(2):192-8.

6. Jones KL, Tonkin A, Horowitz M, Wishart JM, Carney BI, Guha S, Green L. Rate of gastric emptying is a determinant of postprandial hypotension in non-insulin-dependent diabetes mellitus. Clin Sci (Lond). 1998;94:65-70.

7. Vanis L, Gentilcore D, Rayner CK, Wishart JM, Horowitz M, Feinle-Bisset C, Jones KL. Effects of small intestinal glucose load on blood pressure, splanchnic blood flow, glycemia, and GLP-1 release in healthy older subjects. Am J Phys. 2011;300(6):R1524-31.

8. O'Donovan D, Feinle C, Tonkin A, Horowitz M, Jones KL. Postprandial hypotension in response to duodenal glucose delivery in healthy older subjects. J Physiol. 2002;540(Pt 2):673-9.

9. Trahair LG, Horowitz M, Jones KL. Postprandial hypotension is associated with more rapid gastric emptying in healthy older individuals. J Am Med Dir Assoc. 2015;16:521-3.

10. Jordan J, Shannon JR, Grogan E, Biaggioni I, Robertson D. A potent pressor response elicited by drinking water. Lancet. 1999;353(9154):723.

11. Jordan J, Shannon JR, Black BK, Ali Y, Farley M, Costa F, Diedrich A, Robertson RM, Biaggioni I, Robertson D. The pressor response to water drinking in humans : a sympathetic reflex? Circulation. 2000;101(5):504-9.

12. Cariga P, Mathias CJ. Haemodynamics of the pressor effect of oral water in human sympathetic denervation due to autonomic failure. Clin Sci (Lond). 2001;101(3):313-9.
13. Gentilcore D, Meyer JH, Rayner CK, Horowitz M, Jones KL. Gastric distension attenuates the hypotensive effect of intraduodenal glucose in healthy older subjects. Am J Phys. 2008;295(2):R472-7.

14. Breuer HW. Review of acarbose therapeutic strategies in the long-term treatment and in the prevention of type 2 diabetes. Int J Clin Pharmacol Ther. 2003:41(10):421-40.

15. Qualmann C, Nauck MA, Holst JJ, Orskov C, Creutzfeldt W. Glucagon-like peptide 1 (7-36 amide) secretion in response to luminal sucrose from the upper and lower gut. A study using alpha-glucosidase inhibition (acarbose). Scand J Gastroenterol. 1995;30(9):892-6.

16. Enc FY, Imeryuz N, Akin L, Turoglu T, Dede F, Haklar G, Tekesin N, Bekiroglu $\mathrm{N}$, Yegen BC, Rehfeld JF, et al. Inhibition of gastric emptying by acarbose is correlated with GLP-1 response and accompanied by CCK release. Am J Physiol Gastrointest Liver Physiol. 2001;281(3):G752-63.

17. Gentilcore D, Bryant B, Wishart JM, Morris HA, Horowitz M, Jones KL. Acarbose attenuates the hypotensive response to sucrose and slows gastric emptying in the elderly. Am J Med. 2005;118(11):1289.e1285-11.

18. Gentilcore D, Vanis L, Wishart JM, Rayner CK, Horowitz M, Jones KL. The alpha (alpha)-glucosidase inhibitor, acarbose, attenuates the blood pressure and splanchnic blood flow responses to intraduodenal sucrose in older adults. J Gerontol A Biol Sci Med Sci. 2011:66(8):917-24.

19. Madden KM, Harris DE, Meneilly GS. Attenuation of postprandial hypotension with Acarbose in older adults with type 2 diabetes mellitus. J Am Geriatr Soc. 2015;63(7):1484-6.

20. Jian ZJ, Zhou BY. Efficacy and safety of acarbose in the treatment of elderly patients with postprandial hypotension. Chin Med J. 2008;121(20):2054-9.

21. Qiao W, Li J, Li Y, Qian D, Chen L, Wei X, Jin J, Wang Y. Acarbose, the alphaglucosidase inhibitor, attenuates the blood pressure and splanchnic blood flow responses to meal in elderly patients with postprandial hypotension concomitant with abnormal glucose metabolism. Blood Press Monit. 2016; 21(1):38-42

22. Gentilcore D, Chaikomin R, Jones KL, Russo A, Feinle-Bisset C, Wishart JM, Rayner CK, Horowitz M. Effects of fat on gastric emptying of and the glycemic, insulin, and incretin responses to a carbohydrate meal in type 2 diabetes. J Clin Endocrinol Metab. 2006;91(6):2062-7.

23. Gentilcore D, Doran S, Meyer JH, Horowitz M, Jones KL. Effects of intraduodenal glucose concentration on blood pressure and heart rate in healthy older subjects. Dig Dis Sci. 2006;51(4):652-6.

24. Russo A, Stevens JE, Wilson T, Wells F, Tonkin A, Horowitz M, Jones KL. Guar attenuates fall in postprandial blood pressure and slows gastric emptying of oral glucose in type 2 diabetes. Dig Dis Sci. 2003;48(7):1221-9.

25. Jones KL, Maclntosh C, Su YC, Wells F, Chapman IM, Tonkin A, Horowitz M. Guar gum reduces postprandial hypotension in older people. J Am Geriatr Soc. 2001;49(2):162-7.

26. Jones KL, O'Donovan D, Russo A, Meyer JH, Stevens JE, Lei Y, Keogh J, Tonkin A, Horowitz M. Effects of drink volume and glucose load on gastric emptying and postprandial blood pressure in healthy older subjects. Am J Phys. 2005;289(2):G240-8.

27. O'Donovan D, Horowitz M, Russo A, Feinle-Bisset C, Murolo N, Gentilcore D, Wishart JM, Morris HA, Jones KL. Effects of lipase inhibition on gastric emptying of, and on the glycaemic, insulin and cardiovascular responses to, a high-fat/carbohydrate meal in type 2 diabetes. Diabetologia. 2004;47(12): 2208-14.

28. O'Donovan D, Feinle-Bisset C, Chong C, Cameron A, Tonkin A, Wishart J, Horowitz $\mathrm{M}$, Jones $\mathrm{KL}$. Intraduodenal guar attenuates the fall in blood pressure induced by glucose in healthy older adults. J Gerontol A Biol Sci Med Sci. 2005;60(7):940-6.

29. Gentilcore D, Little TJ, Feinle-Bisset C, Samsom M, Smout AJ, Horowitz M, Jones KL. Role of 5-hydroxytryptamine mechanisms in mediating the effects of small intestinal glucose on blood pressure and antropyloroduodenal motility in older subjects. Am J Physiol Gastrointest Liver Physiol. 2007; 293(4):G692-8.

30. Perko MJ. Duplex ultrasound for assessment of superior mesenteric artery blood flow. Eur J Vasc Endovasc Surg. 2001;21(2):106-17.

31. Chan JC, Wong RY, Cheung CK, Lam P, Chow CC, Yeung VT, Kan EC, Loo KM, Mong MY, Cockram CS. Accuracy, precision and user-acceptability of self blood glucose monitoring machines. Diabetes Res Clin Pract. 1997;36(2): 91-104.

32. Arora RR, Bulgarelli RJ, Ghosh-Dastidar S, Colombo J. Autonomic mechanisms and therapeutic implications of postural diabetic cardiovascular abnormalities. J Diabetes Sci Technol. 2008;2(4):645-57. 
33. Piha SJ. Cardiovascular autonomic reflex tests: normal responses and agerelated reference values. Clin Physiol. 1991;11(3):277-90.

34. Ewing DJ, Clarke BF. Diagnosis and management of diabetic autonomic neuropathy. Br Med J Clin Res Ed. 1982;285(6346):916-8.

35. Shibao C, Gamboa A, Diedrich A, Dossett C, Choi L, Farley G, Biaggioni I. Acarbose, an alpha-glucosidase inhibitor, attenuates postprandial hypotension in autonomic failure. Hypertension. 2007;50(1):54-61.

36. Trahair LG, Horowitz M, Hausken T, Feinle-Bisset C, Rayner CK, Jones KL. Effects of exogenous glucagon-like peptide-1 on the blood pressure, heart rate, mesenteric blood flow, and glycemic responses to intraduodenal glucose in healthy older subjects. J Clin Endocrinol Metab. 2014;99(12): E2628-34.

37. Jones KL, Rigda RS, Buttfield MDM, Hatzinikolas S, Pham HT, Marathe CS, WU T, Lange K, Trahair LG, Rayner CK, et al. Effects of lixisenatide on postprandial blood pressure, gastric emptying and glycaemia in healthy people and people with type 2 diabetes. Diab Obes Metab. 2019:21(5)

38. Fukushima T, Asahina M, Fujinuma Y, Yamanaka Y, Katagiri A, Mori M, Kuwabara S. Role of intestinal peptides and the autonomic nervous system in postprandial hypotension in patients with multiple system atrophy. J Neurol. 2013;260(2):475-83.

39. Baggio LL, Drucker DJ. Clinical endocrinology and metabolism. Glucagonlike peptide-1 and glucagon-like peptide-2. Best Pract Res Clin Endocrinol Metab. 2004;18(4):531-54.

40. Bremholm L, Hornum M, Henriksen BM, Larsen S, Holst JJ. Glucagon-like peptide-2 increases mesenteric blood flow in humans. Scand J Gastroenterol. 2009:44(3):314-9.

41. Vanis L, Gentilcore D, Lange K, Gilja OH, Rigda RS, Trahair LG, Feinle-Bisset C, Rayner CK, Horowitz M, Jones KL. Effects of variations in intragastric volume on blood pressure and splanchnic blood flow during intraduodenal glucose infusion in healthy older subjects. Am J Physiol. 2012;302(4):R391-399.

\section{Publisher's Note}

Springer Nature remains neutral with regard to jurisdictional claims in published maps and institutional affiliations.

Ready to submit your research? Choose BMC and benefit from:

- fast, convenient online submission

- thorough peer review by experienced researchers in your field

- rapid publication on acceptance

- support for research data, including large and complex data types

- gold Open Access which fosters wider collaboration and increased citations

- maximum visibility for your research: over $100 \mathrm{M}$ website views per year

At $\mathrm{BMC}$, research is always in progress.

Learn more biomedcentral.com/submissions 